\title{
Working Towards Inclusive, Socially Accountable and Resilient Community Health Systems: An Introduction to
} a Special Issue

\author{
Charles Michelo $^{1}{ }^{\circledR}$, Anna-Karin Hurtig ${ }^{\circledR}$, Helen Schneider ${ }^{3^{*}}{ }^{\circledR}$
}

\begin{abstract}
This editorial introduces the eleven papers in the special issue titled: The multiple lenses on the community health system: implications for research and action. Our editorial begins by describing the collaboration that led to the special issue, and then gives an overview of the contents of the special issue, which include two framing papers and nine empirical contributions from researchers in Zambia, Tanzania, Sweden, South Africa, India, and Australia. We conclude by considering how these papers collectively speak to the theme of resilience.

Keywords: Primary Healthcare, Resilience, Trust, Community Health Systems

Copyright: @ 2022 The Author(s); Published by Kerman University of Medical Sciences. This is an open-access article distributed under the terms of the Creative Commons Attribution License (https://creativecommons.org/licenses/ by/4.0), which permits unrestricted use, distribution, and reproduction in any medium, provided the original work is properly cited.

Citation: Michelo C, Hurtig AK, Schneider H. Working towards inclusive, socially accountable and resilient community health systems: an introduction to a special issue. Int J Health Policy Manag. 2022;11(1):1-4. doi:10.34172/ijhpm.2021.166
\end{abstract}

Article History:

Received: 24 November 2021 Accepted: 4 December 2021 ePublished: 13 December 2021

View Video Summary

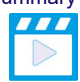

*Correspondence to:

Helen Schneider

Email:

hschneider@uwc.ac.za

\section{Background}

The 40th anniversary of the Alma Ata Declaration on primary healthcare (PHC), in the context of the Sustainable Development Goals, has provoked a re-valuing of the idea of 'community' in health systems. ${ }^{1,2}$ In the World Health Organization's (WHO's) recent PHC Operational Framework, 'empowered people and communities' are one of three pillars of PHC, alongside 'multisectoral policy and action' and 'integrated health services.' ${ }^{3}$ Most would agree that these foundational elements of PHC - in particular the first two remain aspirations rather than realities in most health systems. Nevertheless, over the last years, the pendulum has swung firmly in favour of 'community health' - typically bringing together ideas of community participation and communitybased service provision - and increasingly becoming the subject of formal policies and programmes.

Mindful of this global context, this special issue on the theme of community health systems (CHS) has been coedited in a collaboration between health policy and system researchers from the Universities of Zambia, Western Cape (South Africa), and Umeå (Sweden). In mid-2019 we hosted a gathering at the Chaminuka Lodge in Lusaka, Zambia, where over one week, we followed a structured process of pooling our collective insights on the elements and purposes of CHS. The result was a typology of four key 'lenses' on the CHS, articulated as 'programmatic,' 'relational', 'collective action' and 'critical' lenses, representing different positionalities and purposes in the CHS. We also developed a set of research priorities and compiled a joint 'Chaminuka Manifesto on the Community Health System, outlining a set of common values and ethical stances for research and practice in the CHS. ${ }^{4}$

There are eleven papers in the issue, two of which are short communications authored by the Chaminuka collective, followed by nine empirical contributions from Zambia, Tanzania, Sweden, South Africa, India, and Australia.

This special issue complements other recent efforts offering new thinking on community health..$^{5-7}$ It is distinctive in being conceived and authored by embedded researchers close to country policy and implementation processes. To use Seye Abimbola's framing, ${ }^{8}$ the papers have a local 'pose', and they address themes peculiar to specific contexts, with a 'gaze' that could also be considered 'local.' Why then would we seek to collate these case studies in an international journal, ie, for a foreign audience? The answer to this lies firstly, in the relevance of complex, 'organic' as opposed to specific 'surgical' knowledge ${ }^{8}$ on the CHS for lesson learning across jurisdictions. Thick descriptions from one context may provoke others in similar or even different settings to think afresh about their own realities; they may also widen the scope of what to study in the CHS, beyond well-established instrumental foci such as maternal-child health programmes. The papers touch on a diverse range of themes, for example, community dynamics in rural health worker retention, the politics of the policy process, collective action in times of crisis and mechanisms of responsiveness. Secondly, the papers, when seen together, represent a natural way in which system complexity must be examined; the knowledge generated from such multifaceted viewpoints can be considered a public health good applicable in both local and global social and geographical scales. 


\section{A Synopsis of the Papers}

The first paper which frames the series is titled The Multiple Lenses on the Community Health System: implications for policy, practice, and research, and elaborates the four key lenses and their implications for policy, practice and research. These lenses reflect the multidisciplinary collaboration underpinning this special issue and capture something of the terrain that is the CHS. We do not seek to elevate any of the lenses as more relevant or valid than another, but rather propose the necessity of holding them simultaneously for meaningful action on the CHS, even if the lenses appear to be opposites. The second short communication reports on the structured process adopted to arrive at the research priorities for the CHS and the manifesto.

The nine papers which follow the two framing papers represent the four lenses. Several papers are written through a relational lens, showing the salience of research on social dynamics within the CHS. Two explicitly foreground the role of trust in shaping performance - Zulu and colleagues ${ }^{9}$ explore how prioritising trust relations unlocked access to care for the stigmatized condition of hydrocoele in Zambia, while Assegaai and Schneider ${ }^{10}$ conversely describe how wider institutional mistrust generated low interpersonal trust between frontline actors in a community health worker programme. Mathias et $\mathrm{al}^{11}$ conducted participatory action research which surfaced unique local knowledge for the design of mental health care in Uttarakhand State, India. Finally, Sirili et al $^{12}$ offer novel insights into rural health worker retention in Tanzania by locating the problem as one of relationships with the community - either accommodation or rejection - rather than the usual focus on health system (supply side) incentives.

Two papers illustrate the critical lens on the CHS. Drawing on the experience of Australia, Baum and Freeman ${ }^{13}$ analyse the political economy, namely the ideas, interests, and institutions, of why CHS do not flourish in high income countries. They point to the power of biomedicine and a retreat from investment in public PHC under neoliberalism. Another of the contributions from the Zambian collective illustrates how a confusing array of (mostly international) actors and interests behind the development of a community health strategy crowded out frontline provider and community perspectives.

In a case study of collective action, van Ryneveld and colleagues ${ }^{14}$ write about the mobilization of community action networks across Cape Town in response to the livelihood and social crisis precipitated by the harsh lockdowns at the start of the coronavirus disease 2019 (COVID-19) pandemic. They reprise the central role of trust relations in enabling a rapid mobilization of the community action networks, which they refer to as "moving at the speed of trust." The authors also describe the difficulties of a fluid and self-organised social movement attempting to engage formalised state responses, an indication of the gap between the easy rhetoric of social mobilization and its reality in practice.

Finally, two of the papers, from Sweden and South Africa, address the design and implementation of strategies in the $\mathrm{CHS}$ at a more macro level, and are in part programmatic and in part relational in their lenses. Using a realist methodology, Jonsson and colleagues ${ }^{15}$ unpack the mechanisms at play in the shift from innovator sites to scale up of 'virtual health rooms' in communities of rural northern Sweden, providing insights into the necessary conditions for such a transition that include, amongst others, relationships of trust. Sutherns and Olivier ${ }^{16}$ map the mechanisms for receiving and responding to citizen feedback - complaints, hotlines, facility committees and satisfaction surveys, amongst others - in the public health system of one South African province, concluding on the need for far greater synergy if these mechanisms are to amount to meaningful 'health system responsiveness.'

\section{Resilience, Trust and the Community Health Systems}

Ultimately, the intention of these papers is to appreciate the role of the CHS more fully within health systems and to understand how to nurture its functioning. Our starting point is to acknowledge CHS functioning as an inherently contested idea, with many viewpoints, explanations, and reflections. Listening to the 'voices' of the papers in this collection, however, we would argue that the processes that lead to such functioning can be referred to as a kind of CHS resilience, and the drivers that shape or worsen resilience is the knowledge these papers bring.

Resilience here is understood as a response to both sudden shocks, such as COVID-19, ${ }^{17}$ as well as chronic stressors ${ }^{18}$; and crucially, the capacity to go beyond absorption or (mal)adaptation to one of transformation, able to challenge the causes of shocks and stressors. ${ }^{18}$ As several of the papers illustrate, such 'process resilience' requires ways of functioning, including leadership, coordinated priority setting, empowered individuals with agency able to operate flexibly, communities that work together, inclusion and participation and effective planning and coordination around the common goal of responding to people's health needs. ${ }^{19,20}$ The key output of process resilience is trust, a central theme in the papers, whether in the participatory design of mental health care in Uttarakhand, community mobilisation in South Africa, integration of virtual health rooms in Sweden or the uptake of hydrocoele treatment in Zambia. CHS resilience is nurtured through community actions and actors that enhance trust.

More broadly, we think that interpreting CHS functioning as a combination of processes, outputs and outcomes of resilience adds a new dimension to the debate of what has not worked and why in PHC; what could work; and what can inform policy and practice as a necessary prerequisite to realising the Alma Ata Declaration on $\mathrm{PHC}^{21}$ We would go further to assert that without strengthening CHS resilience, universal health coverage will be unattainable. ${ }^{18}$

The system wide and potentially transformative role of the CHS is, however, far from being recognised and even less achieved. In most settings, the CHS is moribund, treated as a subordinate sphere within health system hierarchies, with inequitable status and poor connections to the overall health system, and little deliberate investment. ${ }^{22}$ This has been most vividly demonstrated in the ravages of COVID-19, especially in contexts where community engagement and 
trust relations are weak and the CHS is poorly integrated into national health systems. ${ }^{23}$ Building a resilient CHS remains a monumental challenge. It encompasses layers of complexity, as systems must establish links from national governments to households, from the public to the private sphere, and from health to other sectors. ${ }^{6,18}$

To achieve CHS resilience, the interface between community health and the overall health system must be enabled by deliberate acts, underpinned by an information base, governance that addresses power asymmetries, local finance systems and effective health delivery. However, our investments should be multi-pronged, requiring not just hardware, but also the software of relationships which emanate from appropriate community engagement, empowerment, mutually accountable partnerships, and equitable processes led by trusted governors.

\section{Acknowledgements}

We are deeply indebted to the IJHPM editorial team for so readily embracing the idea of this special issue. The journal plays a uniquely interesting role, not least of which is that it publishes papers from across the global North and South, and has an epistemic inclusivity that mirrors what we believe is required in policy, practice and research on CHS.

\section{Ethical issues}

Not applicable.

\section{Competing interests}

Authors declare that they have no competing interests.

\section{Authors' contributions}

$\mathrm{CM}, \mathrm{HS}, \mathrm{AKH}$ jointly conceived the editorial; $\mathrm{CM}$ and HS drafted the editorial; all approved the final version.

\section{Funding}

South African National Research Foundation, Swedish STINT and Swedish Research Council.

\section{Authors' affiliations}

'School of Public Health, University of Zambia, Lusaka, Zambia. ${ }^{2}$ Department of Epidemiology and Global Health, Umeå University, Umeå, Sweden. ${ }^{3}$ School of Public Health and SAMRC Health Services to Systems Research Unit, University of the Western Cape, Cape Town, South Africa.

\section{References}

1. Sacks E, Schleiff M, Were M, Chowdhury AM, Perry HB. Communities, universal health coverage and primary health care. Bull World Health Organ. 2020;98(11):773-780. doi:10.2471/blt.20.252445

2. Pfaffmann Zambruni J, Rasanathan K, Hipgrave D, et al. Community health systems: allowing community health workers to emerge from the shadows. Lancet Glob Health. 2017;5(9):e866-e867. doi:10.1016/s2214109x(17)30268-1

3. World Health Organization (WHO), United Nations Children's Fund (UNICEF). Operational Framework for Primary Health Care: Transforming Vision into Action. Geneva: WHO, UNICEF; 2020.

4. Chaminuka collective. Lenses, Metaphors and Research Priorities on Community Health Systems. Report of Workshop, Chaminuka Lodge, Lusaka, Zambia, 10-14 June 2019. Cape Town: Universities of the Western Cape, Zambia and Umeå; 2019.
5. George AS, LeFevre AE, Schleiff M, Mancuso A, Sacks E, Sarriot E. Hubris, humility and humanity: expanding evidence approaches for improving and sustaining community health programmes. BMJ Glob Health. 2018;3(3):e000811. doi:10.1136/bmjgh-2018-000811

6. George AS, Scott K, Mehra V, Sriram V. Synergies, strengths and challenges: findings on community capability from a systematic health systems research literature review. BMC Health Serv Res. 2016;16(Suppl 7):623. doi:10.1186/s12913-016-1860-1

7. Sacks E, Morrow M, Story WT, et al. Beyond the building blocks: integrating community roles into health systems frameworks to achieve health for all. BMJ Glob Health. 2018;3(Suppl 3):e001384. doi:10.1136/ bmjgh-2018-001384

8. Abimbola $\mathrm{S}$. The foreign gaze: authorship in academic global health. $B M J$ Glob Health. 2019;4(5):e002068. doi:10.1136/bmjgh-2019-002068

9. Zulu JM, Maritim P, Silumbwe A, et al. Unlocking trust in community health systems: lessons from the lymphatic filariasis morbidity management and disability prevention pilot project in Luangwa District, Zambia. Int $\mathrm{J}$ Health Policy Manag. 2021. doi:10.34172/ijhpm.2021.133

10. Assegaai T, Schneider H. Factors associated with workplace and interpersonal trust in the supervisory system of a community health worker programme in a rural South African District. Int $\mathrm{J}$ Health Policy Manag. 2021. doi:10.34172/ijhpm.2021.03

11. Mathias K, Rawat M, Thompson A, Gaitonde R, Jain S. Exploring community mental health systems - a participatory health needs and assets assessment in the Yamuna Valley, North India. Int J Health Policy Manag. 2021. doi:10.34172/ijhpm.2020.222

12. Sirili N, Simba D, Zulu JM, Frumence G, Tetui M. Accommodate or Reject: The Role of Local Communities in the Retention of Health Workers in Rural Tanzania. Int J Health Policy Manag. 2021. doi:10.34172/ijhpm.2021.77

13. Baum F, Freeman T. Why community health systems have not flourished in high income countries: what the Australian experience tells us. Int $\mathrm{J}$ Health Policy Manag. 2021. doi:10.34172/ijhpm.2021.42

14. van Ryneveld M, Whyle E, Brady L. What Is COVID-19 Teaching Us About Community Health Systems? A Reflection From a Rapid Community-Led Mutual Aid Response in Cape Town, South Africa. Int J Health Policy Manag. 2021. doi:10.34172/ijhpm.2020.167

15. Jonsson F, Carson DB, Goicolea I, Hurtig A-K. Strengthening Community Health Systems Through Novel eHealth Initiatives? Commencing a Realist Study of the Virtual Health Rooms in Rural Northern Sweden. Int J Health Policy Manag. 2021. doi:10.34172/ijhpm.2021.08

16. Sutherns T, Olivier J. Mapping the multiple health system responsiveness mechanisms in one local health system: a scoping review of the Western Cape provincial health system of South Africa. Int J Health Policy Manag. 2021. doi:10.34172/ijhpm.2021.85

17. Bridgland VME, Moeck EK, Green DM, et al. Why the COVID-19 pandemic is a traumatic stressor. PLoS One. 2021;16(1):e0240146. doi:10.1371/ journal.pone. 0240146

18. Barasa EW, Cloete K, Gilson L. From bouncing back, to nurturing emergence: reframing the concept of resilience in health systems strengthening. Health Policy Plan. 2017;32(Suppl_3):iii91-iii94. doi:10.1093/heapol/czx118

19. Gilson L, Barasa E, Nxumalo N, et al. Everyday resilience in district health systems: emerging insights from the front lines in Kenya and South Africa. BMJ Glob Health. 2017;2(2):e000224. doi:10.1136/bmjgh-2016-000224

20. Topp SM. Power and politics: the case for linking resilience to health system governance. BMJ Glob Health. 2020;5(6):e002891. doi:10.1136/ bmjgh-2020-002891

21. Walraven G. The 2018 Astana Declaration on primary health care, is it useful? J Glob Health. 2019;9(1):010313. doi:10.7189/jogh.09.010313

22. Biddle L, Wahedi K, Bozorgmehr K. Health system resilience: a literature review of empirical research. Health Policy Plan. 2020;35(8):1084-1109. doi:10.1093/heapol/czaa032

23. Haldane V, De Foo C, Abdalla SM, et al. Health systems resilience in managing the COVID-19 pandemic: lessons from 28 countries. Nat Med. 2021;27(6):964-980. doi:10.1038/s41591-021-01381-y 


\section{Special Issue Editors}

Lead Co-Editor

Helen Schneider is a public health specialist and health systems and policy researcher who has worked for more than 25 years on South Africa's health system. She joined the School of Public Health at the University of the Western Cape in 2011 and was its Director from 2013 to 2016. Since 2015, she has been the director of the UWC/MRC Health Services to Systems Research Unit, and in 2016 was awarded a South African Research Chair in Health Systems Governance. Helen's current research and policy interests include community health systems, including South Africa's Ward Based Outreach Team Strategy; governance and leadership of national community health worker programmes; approaches to district health system strengthening and governance; and more recently, the governance of intersectoral action for health.

\section{Co-Editor}

Anna-Karin Hurtig is professor in public health with a focus on health policy and systems research. She is currently the Head of the Department of Epidemiology and Global Health at Umeå University, Sweden. She has collaborated in research and capacity building in areas of Primary Healthcare for more than twenty years, mainly in several sub-Saharan countries. During the last years she has increasingly been involved in health systems research in Sweden. She serves on the board of the Swedish Association for Social Medicine and Public Health and in the Committee for Development Research of the Swedish Research Council. After practising clinical medicine, she pursued further studies in public health and obtained Master's and Doctoral degrees from London School of Hygiene and Tropical Medicine.

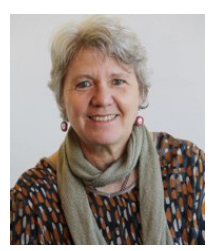

\section{Co-Editor}

Charles Michelo is a Professor of Epidemiology and Founding Dean of the first School Public Health in Zambia, housed at the University of Zambia where he also is Director for the Strategic Centre for Health Systems Metrics and Evaluations (SCHEME). He is currently Director for Harvest Research Institutes at Harvest University in Lusaka, Zambia. He has a foundational medical degree and MPH from Zambia, MBA from Edith Cowan University in Perth, Australia and Epidemiology doctorate from Bergen, Norway. His main work has been on health systems over a 20 year career that has evolved into several off shoots including work in priority setting and community health systems, leading to his current research in Disparities and Equity together with the Countdown 2030 group; Human Resources for Primary Care Leadership and Bioethics through Health Systems Global group. Recently, he has embedded his equity research in NCDs, reproductive, maternal, neonatal, child and adolescent health, and emerging infections as part of HIV related comorbidities.

\section{Co-Editor}

Joseph Mumba Zulu is an Associate Professor of Community Health in the School of Public Health, and Director for the Institute of Distance Education at the University of Zambia. He is specialised in Social Work, Social and Medical Anthropology as well as Public Health. Prof Zulu has formerly worked as Assistant Dean -Research for the School of Public Health and Program Manager for the Master's in Public Health with Implementation Research supported by the Tropical Disease Research (TDR). He has extensive professional and research experience with local and international institutions in community-based health workers, health policy and systems, gender, infectious diseases, research ethics, sexual and reproductive health as well as child protection.

\section{Co-Editor}

Uta Lehmann is a social scientist by training and has worked in public health and health personnel education for 30 years. She joined the SOPH in 1999, and has been its director from 2009 to 2012, and again since 2017. Her interests and expertise lie in health policy and systems research, human resource development, and qualitative research. Her research projects have included a focus on understanding how relationships, power and politics impact on how health systems function, and exploring ways to support the voice and capacity of frontline providers and community health workers. She has led capacity strengthening initiatives for human resources development with sister institutions in other African countries and with international partners. She works extensively with the WHO and is the co-ordinator of the WHO Collaborating Centre for research and training in human resources for health.

\section{Co-Editor}

Miguel San Sebastian is a medical doctor with a MSc degree in control of infectious diseases and a Ph.D. degree in environmental epidemiology from the London School of Hygiene and Tropical Medicine. He practiced public health during 12 years among indigenous communities of the Amazon basin of Ecuador. Currently working as Professor in Public Health at the Department of Epidemiology and Global Health, Umeå university, teaching different courses (public health, epidemiology, social epidemiology) at Master and PhD level. His current research is focused on strengthening health systems in low-income countries and social inequalities in health in the Swedish context. He is also part of the Norrland's Observatory for Equity in Health and Health Care (NOEHHC).
